\title{
State Analysis of Time-Varying Singular Bilinear Systems by RK-Butcher Algorithms
}

\author{
V. Murugesh, K. Batri
}

\begin{abstract}
The Runge-Kutta (RK)-Butcher algorithm is used to study the timevarying singular bilinear systems with the exact solutions. The results (discrete solutions) obtained using the Haar wavelets, Single-Term Walsh series (STWS) and RK-Butcher algorithms are compared with the exact solutions of the time-varying singular bilinear systems. It is found that the solution obtained using the RK-Butcher algorithm is closer to the exact solutions of the time-varying singular bilinear systems. The RK-Butcher algorithm can easily be implemented using a digital computer and the solution can be obtained for any length of time, which is an added advantage of this algorithm.
\end{abstract}

Keywords: Time-varying singular bilinear systems, Haar wavelets, Runge-Kutta Butcher algorithm, STWS algorithm.

\section{Introduction}

The development of singular bilinear systems has been studied by some researchers. Campbell [1] had done some preliminary work, but there was no available closed-form solution in that paper. In some analysis of neural networks, both singular systems [2] and bilinear systems [3] have been used. The multipliers and algebraic interconnections between singular systems and bilinear systems are allowed in dynamical systems. For singular bilinear systems, Lewis et al. [4] have been discussed extensively in the literature. However, the solution due to Lewis et al. only applies for the time-invariant case. Hsiao and Wang [5] applied the Haar wavelets for the solution of time -varying singular bilinear systems. Sepehrian and Razzaghi [6] applied the STWS approach for finding the numerical solution of time-varying bilinear systems.

Runge-Kutta (RK) methods have become very popular both as computational techniques and as a topic for research [7-12]. Butcher [8] derived the best RK pair, together with an error estimate, and in all statistical measures this approach is known as the RK-Butcher algorithm. This algorithm appears to be of sixth order because it requires six function evaluations, but in practice the 'working order' is closer to five (fifth order). However, the accuracy of the results obtained is better than that of all other algorithms examined including the RK- Fehlberg, RK-Merson, RK-centroidal mean (RKCeM) and RK-arithmetic mean (RKAM) algorithms.

Murugesh and Murugesan [13-15] introduced the RK-Butcher algorithm in Raster and Time-multiplexing CNN simulations. Recently, $[16,18]$ the RK-Butcher algorithm is used to find the numerical solution of an industrial application problem. In this article, we present a new approach for solving the time-varying singular bilinear systems using the RK-Butcher algorithm with more accuracy.

\section{The RK-Butcher Algorithm}

The normal order of an RK algorithm is the approximate number of leading terms of an infinite Taylor series which calculates the trajectory of a moving point [17]. The remainder of the infinite sum, which is excluded, is referred to as the local truncation error (LTE). These RK algorithms are forward-looking predictors, i.e. they do not use any information from preceding steps to predict the future position of a point. For this reason, they require a minimum of input data and consequently are very simple to program and use. 
The general $p$-stage Runge-Kutta method for solving an IVP is

$$
y^{\prime}=f(x, y)
$$

with the initial condition $y\left(x_{0}\right)=y_{0}$ is defined by

$$
y_{n+1}=y_{n}+h \sum_{i=1}^{p} b_{i} k_{i}
$$

where

$$
k_{i}=f\left(x_{n}+c_{i} h, y_{n}+h \sum_{j=1}^{p} a_{i j} k_{j}\right), \quad i=1,2,3, \ldots \ldots, p
$$

and

$$
c_{i}=\sum_{j=1}^{p} a_{i j}, \quad i=i, 2,3, \ldots . ., p
$$

In the preceding equations $\mathrm{c}$ and $\mathrm{b}$ are $\mathrm{p}$-dimensional vectors and $\mathrm{A}\left(a_{i j}\right)$ is the $p \times p$ matrix. Then the Butcher array takes the form

$$
\begin{array}{l|llll}
c_{1} & a_{11} & & & \\
c_{2} & a_{21} & a_{22} & & \\
c_{3} & a_{31} & a_{32} & a_{33} & \\
\cdot & \cdot & \cdot & \cdot & \\
\cdot & \cdot & \cdot & \cdot & \\
\cdot & \cdot & \cdot & \cdot & \\
\cdot & \cdot & \cdot & \cdot & \cdot \\
c_{p} & a_{p 1} & a_{p 2} & a_{p 3} & a_{p p} \\
\hline & b_{1} & b_{2} & b_{p-1} & b_{p}
\end{array}
$$

The RK-Butcher algorithm of equation (1) is of the form

$$
\begin{aligned}
& k_{1}=h f\left(x_{n}, y_{n}\right) \\
& k_{2}=h f\left(x_{n}+\frac{h}{4}, y_{n}+\frac{k_{1}}{4}\right) \\
& k_{3}=h f\left(x_{n}+\frac{h}{4}, y_{n}+\frac{k_{1}}{8}+\frac{k_{2}}{8}\right) \\
& k_{4}=h f\left(x_{n}+\frac{h}{2}, y_{n}-\frac{k_{2}}{2}+k_{3}\right) \\
& k_{5}=h f\left(x_{n}+\frac{3 h}{4}, y_{n}+\frac{3 k_{1}}{16}+\frac{9 k_{4}}{16}\right) \\
& k_{6}=h f\left(x_{n}+h, y_{n}-\frac{3 k_{1}}{7}+\frac{2 k_{2}}{7}+\frac{12 k_{3}}{7}-\frac{12 k_{4}}{7}+\frac{8 k_{5}}{7}\right)
\end{aligned}
$$

$5^{\text {th }}$ order predictor

$$
y_{n+1}=y_{n}+\frac{1}{90}\left(7 k_{1}+32 k_{3}+12 k_{4}+32 k_{5}+7 k_{6}\right)
$$

$4^{\text {th }}$ order predictor

$$
y_{n+1}^{*}=y_{n}+\frac{1}{6}\left(k_{1}+4 k_{4}+k_{6}\right)
$$

The local truncation error estimate $(\mathrm{EE})$ is

$$
E E=y_{n+1}-y_{n+1}^{*}
$$

Then the formation of the Butcher array of the above equation (2) takes the following form 


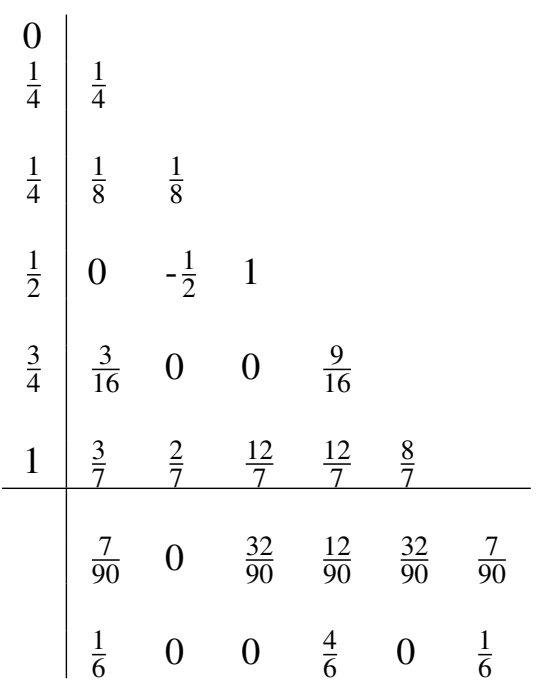

\section{Analysis of Time-Varying Singular Bilinear Systems}

Consider the linear first order time-varying singular system

$$
K \dot{x}(t)=A x(t)+B(t) u(t)
$$

with $x_{0}=x(0)$, where $\mathrm{K}$ is an $n \times n$ singular matrix, $\mathrm{A}$ is an $n \times n$ matrix, $\mathrm{B}$ is an $n \times r$ matrix. $\mathrm{x}(\mathrm{t})$ is $\mathrm{n}$-state vectors and $\mathrm{u}(\mathrm{t})$ is an $\mathrm{r}$-input vector.

The time-varying singular bilinear system is of the form

$$
E(t) \dot{x}(t)=A(t) x(t)+\sum_{i=1}^{q} N_{i}(t) x(t) u_{i}(t)+B(t) u(t)
$$

equation (4)is written in the form (3) as

$$
E(t) \dot{x}(t)=\left(A(t)+\sum_{i=1}^{q} N_{i}(t) u_{i}(t)\right) x(t)+B(t) u(t)
$$

where the singular matrix $E(t) \in R^{n \times n}$, the state $x(t) \in R^{n}$, the control $u(t) \in R^{q}, A(t) \in R^{n \times n}$ and $B(t) \in R^{n \times q} . N_{i}(t) \in R^{n \times n}$ and $u_{i}(t), i=1,2,3, \ldots ., q$, are the components of $u(t)$. The response $x(t), 0 \leq$ $t \leq t_{i}$, is required to be found. The time-varying singular bilinear systems are much more difficult to solve than the time invariant singular bilinear systems. Therefore, many authors have tried various transform methods to over come these difficulties. In this article, we introduce RK-Butcher algorithms with more accuracy to solve these time-varying singular bilinear systems.

\section{Numerical Example}

Consider the time-varying singular bilinear system of the following form (Hsiao and Wang [5]) and Sepehrian and Razzaghi[6]).

$$
\begin{aligned}
& E(t)=\left[\begin{array}{ccc}
0 & -t & 0 \\
1 & 0 & t \\
0 & 1 & 0
\end{array}\right] A(t)=\left[\begin{array}{ccc}
-2 & t & 1 \\
0 & -4 & 2 \\
-2 t & 0 & 1
\end{array}\right] N_{1}(t)=\left[\begin{array}{ccc}
1 & -t & 1 \\
0 & 3 & -2 \\
2 t & 0 & -2
\end{array}\right] \\
& B(t)=\left[\begin{array}{lll}
2 & 1 & 3
\end{array}\right]^{T}, u(t)=1 \text {, with initial condition } x(0)=\left[\begin{array}{lll}
12 & 2 & 5
\end{array}\right]^{T}
\end{aligned}
$$


when we solve (5), the analytic solution for $x(t)$ can be shown as

$$
x(t)=\left[\begin{array}{l}
(2-t)\left(\exp \left(\frac{-t}{2}\right)+\exp (t)\right)+8 \\
2 \exp \left(\frac{-t}{2}\right)-\exp (t)+1 \\
\exp \left(\frac{-t}{2}\right)+\exp (t)+3
\end{array}\right]
$$

The discrete solutions of equation (5) are evaluated using the RK-Butcher algorithms (with step size $\mathrm{t}=0.25$ ) represented in equation (2) and the results are compared with the solutions obtained by the Haar wavelets method by Hsiao and Wang [5] and the STWS method by Sepehrian and Razzaghi [6]. The results are shown in tables 1 - 3 along with the exact solutions calculated using equation (7). Errors between the exact and discrete solutions are also given in Tables 1 - 3 .

\begin{tabular}{|l|l|l|l|l|l|l|l|l|}
\hline \multirow{2}{*}{ S.No } & \multirow{2}{*}{ Time } & \multicolumn{9}{|c|}{$\begin{array}{l}\text { Discrete solution } x_{1} \text { Values } \\
\text { Solutions }\end{array}$} & $\begin{array}{l}\text { Haar } \\
\text { Solutions }\end{array}$ & $\begin{array}{l}\text { Haar } \\
\text { Error }\end{array}$ & $\begin{array}{l}\text { STWS } \\
\text { Solutions }\end{array}$ & $\begin{array}{l}\text { STWS } \\
\text { Error }\end{array}$ & $\begin{array}{l}\text { RK- } \\
\text { Butcher } \\
\text { Solutions }\end{array}$ & $\begin{array}{l}\text { RK- } \\
\text { Butcher } \\
\text { Error }\end{array}$ \\
\hline 1 & 0 & 12.000000 & 12.0000 & 0.000000 & 12.00000 & 0.000000 & 12.000000 & 0.000000 \\
\hline 2 & 0.25 & 11.886053 & 11.8861 & 0.000047 & 11.88605 & 0.000003 & 11.886053 & 0.000000 \\
\hline 3 & 0.5 & 11.791414 & 11.7914 & 0.000014 & 11.79142 & 0.000006 & 11.791414 & 0.000000 \\
\hline 4 & 0.75 & 11.711533 & 11.7115 & 0.000033 & 11.71154 & 0.000007 & 11.711533 & 0.000000 \\
\hline 5 & 1 & 11.641283 & 11.6413 & 0.000017 & 11.64128 & 0.000003 & 11.641283 & 0.000000 \\
\hline 6 & 1.25 & 11.574810 & 11.5748 & 0.000010 & 11.57481 & 0.000000 & 11.574810 & 0.000000 \\
\hline 7 & 1.5 & 11.505362 & 11.5054 & 0.000038 & 11.50537 & 0.000008 & 11.505362 & 0.000000 \\
\hline 8 & 1.75 & 11.425089 & 11.4251 & 0.000011 & 11.42510 & 0.000011 & 11.425089 & 0.000000 \\
\hline 9 & 2 & 11.324812 & 11.3248 & 0.000012 & 11.32481 & 0.000002 & 11.324812 & 0.000000 \\
\hline
\end{tabular}

Table 1: Solutions for the problem at various values of $x_{1}$.

\begin{tabular}{|c|c|c|c|c|c|c|c|c|}
\hline \multirow[b]{2}{*}{ S.No } & \multirow[b]{2}{*}{ Time } & \multicolumn{7}{|c|}{ Discrete solution $x_{2}$ Values } \\
\hline & & $\begin{array}{l}\text { Exact } \\
\text { Solutions }\end{array}$ & $\begin{array}{l}\text { Haar } \\
\text { Solutions }\end{array}$ & $\begin{array}{l}\text { Haar } \\
\text { Error }\end{array}$ & $\begin{array}{l}\text { STWS } \\
\text { Solutions }\end{array}$ & $\begin{array}{l}\text { STWS } \\
\text { Error }\end{array}$ & $\begin{array}{l}\text { RK- } \\
\text { Butcher } \\
\text { Solutions }\end{array}$ & $\begin{array}{l}\text { RK- } \\
\text { Butcher } \\
\text { Error }\end{array}$ \\
\hline 1 & 0 & 2.000000 & 2.0000 & 0.000000 & 2.00000 & 0.000000 & 2.000000 & 0.000000 \\
\hline 2 & 0.25 & 1.745678 & 1.7457 & 0.000022 & 1.74568 & 0.000002 & 1.745678 & 0.000000 \\
\hline 3 & 0.5 & 1.480968 & 1.4810 & 0.000032 & 1.48097 & 0.000002 & 1.480968 & 0.000000 \\
\hline 4 & 0.75 & 1.203067 & 1.2031 & 0.000033 & 1.20307 & 0.000003 & 1.203067 & 0.000000 \\
\hline 5 & 1 & 0.908880 & 0.9089 & 0.000020 & 0.90888 & 0.000000 & 0.908880 & 0.000000 \\
\hline 6 & 1.25 & 0.594985 & 0.5950 & 0.000015 & 0.59498 & 0.000005 & 0.594985 & 0.000000 \\
\hline 7 & 1.5 & 0.257579 & 0.2576 & 0.000021 & 0.25758 & 0.000001 & 0.257579 & 0.000000 \\
\hline 8 & 1.75 & -0.107578 & -0.1076 & 0.000022 & -0.10758 & 0.000002 & -0.107578 & 0.000000 \\
\hline 9 & 2 & -0.505221 & -0.5052 & 0.000021 & -0.50522 & 0.000001 & -0.505221 & 0.000000 \\
\hline
\end{tabular}

Table 2: Solutions for the problem at various values of $x_{2}$.

\section{Conclusions}

The discrete solutions obtained using the RK-Butcher algorithm gives more accurate values when compared to the Haar wavelets method discussed by Hsiao and Wang [5] and the STWS method by 


\begin{tabular}{|c|c|c|c|c|c|c|c|c|}
\hline \multirow[b]{2}{*}{ S.No } & \multirow[b]{2}{*}{ Time } & \multicolumn{7}{|c|}{ Discrete solution $x_{3}$ Values } \\
\hline & & $\begin{array}{l}\text { Exact } \\
\text { Solutions }\end{array}$ & $\begin{array}{l}\text { Haar } \\
\text { Solution }\end{array}$ & $\begin{array}{l}\text { Haar } \\
\text { sError }\end{array}$ & $\begin{array}{l}\text { STWS } \\
\text { Solutions }\end{array}$ & $\begin{array}{l}\text { STWS } \\
\text { Error }\end{array}$ & $\begin{array}{l}\text { RK- } \\
\text { Butcher } \\
\text { Solutions }\end{array}$ & $\begin{array}{l}\text { RK- } \\
\text { Butcher } \\
\text { Error }\end{array}$ \\
\hline 1 & 0 & 5.000000 & 5.0000 & 0.000000 & 5.00000 & 0.000000 & 5.000000 & 0.000000 \\
\hline 2 & 0.25 & 5.072562 & 5.0726 & 0.000038 & 5.07256 & 0.000002 & 5.072562 & 0.000000 \\
\hline 3 & 0.5 & 5.166522 & 5.1665 & 0.000022 & 5.16652 & 0.000002 & 5.166522 & 0.000000 \\
\hline 4 & 0.75 & 5.284021 & 5.2840 & 0.000021 & 5.28402 & 0.000001 & 5.284021 & 0.000000 \\
\hline 5 & 1 & 5.427522 & 5.4275 & 0.000022 & 5.42752 & 0.000002 & 5.427522 & 0.000000 \\
\hline 6 & 1.25 & 5.599862 & 5.5999 & 0.000038 & 5.59986 & 0.000002 & 5.599862 & 0.000000 \\
\hline 7 & 1.5 & 5.804289 & 5.8043 & 0.000011 & 5.80429 & 0.000001 & 5.804289 & 0.000000 \\
\hline 8 & 1.75 & 6.044524 & 6.0445 & 0.000024 & 6.04451 & 0.000014 & 6.044524 & 0.000000 \\
\hline 9 & 2 & 6.324812 & 6.3248 & 0.000012 & 6.32480 & 0.000012 & 6.324812 & 0.000000 \\
\hline
\end{tabular}

Table 3: Solutions for the problem at various values of $x_{3}$.

Sepehrian and Razzaghi [6]. From the tables 1-3, one can observe that the solutions obtained by the RK-Butcher algorithm match well with the exact solutions of the time-varying singular bilinear systems, but the Haar wavelets and STWS methods yields a little error. Hence the RK-Butcher algorithm is more suitable for studying the time-varying bilinear systems.

\section{Bibliography}

[1] Campell, S.L., 1987, Bilinear nonlinear descriptor control systems, CRSC Technical Report 102386-01, Department of Mathematics, N.C. State University, Raleigh, NC 27695.

[2] Declaris, N. and Rindos, A., 1984, Semistate analysis of neural networks in Apysia Californica, Proceedings of the 27th MSCS, 686-689.

[3] Wiener, N., 1948, Cybernetics (Cambridge, MIT Press).

[4] Lewis, F. L., Mertzios, B. C., and Marszalek, W., 1991, Analysis of singular bilinear systems using Walsh functions, IEE Proceedings Part-D,138, 89-92.

[5] Hsiao, C. H., and Wang, W. J., 2000, State Analysis of time-varying Singular Bilinear Systems via Haar wavelets, Mathematics and Computers in Simulation, 52, 11-20.

[6] Sepehrian, B., and Razzaghi, M., 2003, State Analysis of time-varying Singular Bilinear Systmes by Single-Term Walsh Series, International Journal of Computer Mathematics, 80, 413-418.

[7] Alexander, R.K. and Coyle, J.J.,1990, Runge-Kutta methods for differential-algebraic systems. SIAM Journal of Numerical Analysis, 27, 736-752.

[8] Butcher, J.C., 1987, The Numerical Analysis of Ordinary Differential Equations: Runge-Kutta and General Linear Methods (Chichester: JohnWiley).

[9] Butcher, J.C., 2003, Numerical Methods for Ordinary Differential Equations (Chichester: JohnWiley).

[10] Shampine, L.F., 1994, Numerical Solution of Ordinary Differential Equations (NewYork: Chapman \& Hall). 
[11] Yaakub, A.R. and Evans, D.J., 1999, A fourth order Runge-Kutta RK(4,4) method with error control. International Journal of Computer Mathematics, 71, 383-411.

[12] Yaakub, A.R. and Evans, D.J., 1999, New Runge-Kutta starters of multi-step methods. International Journal of Computer Mathematics, 71, 99-104.

[13] Murugesh, V., and Murugesan, K., 2004, Comparison of Numerical Integration Algorithms in Raster CNN Simulation, Lecture Notes in Computer Science, 3285, 115-122.

[14] Murugesh, V. and Murugesan, K., 2005, Simulation of Cellular Neural Networks using the RKButcher algorithm, International Journal of Management and Systems, 21, 65-78.

[15] Murugesh, V., and Murugesan, K., 2006, Simulation of Time-Multiplexing Cellular Neural Networks with Numerical Integration Algorithms, Lecture Notes in Computer Science, 3991, 115-122.

[16] Devarajan Gopal, Murugesh, V., and Murugesan, K., 2006, Numerical Solution of Second-order Robot Arm Control Problem using Runge-Kutta Butcher Algorithm, International Journal of Computer Mathematics, 83, 345-356.

[17] Shampine, L.F. and Gordon, M.K., 1975, Computer Solutions of Ordinary Differential Equations: The Initial Value Problem (San Francisco, CA:W.H. Freeman).

[18] V. Murugesh and K. Batri, "An Efficient Numerical Integration Algorithm for Cellular Neural Network Based Hole-Filler Template Design", International Journal of Computers, Communications \& Control, Vol. II (2007), No. 4, pp. 367-374.

V. Murugesh

Department of Information and Communication Engineering

Hannam University

133 Ojung-dong Daeduk-gu, Daejeon 306-791, Republic of Korea

E-mail: murugesh72@gmail.com

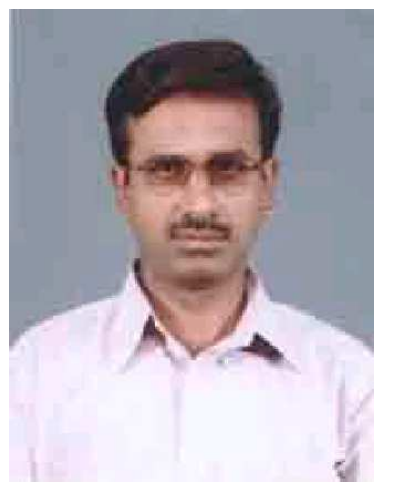

Dr. V. Murugesh obtained his Bachelor of Science in Computer Science and Master of Computer Applications degree from Bharathiar University, Coimbatore, India during 1992 and 1995 respectively. Completed his $\mathrm{PhD}$ in Computer Science from Bharathidasan University, Tiruchirappalli, India during 2006. He has held various positions at National Institute of Technology, Tiruchirappalli, India and Sona College of Technology, Salem, India. Currently, he is working as Assistant Professor in the Department of Information and Communication Engineering at Hannam University, Daejeon, Republic of Korea. His fields of interest are in Neural Network based Image Processing and Scientific computing. He has published more than 30 technical papers in International, National journals and conferences. 


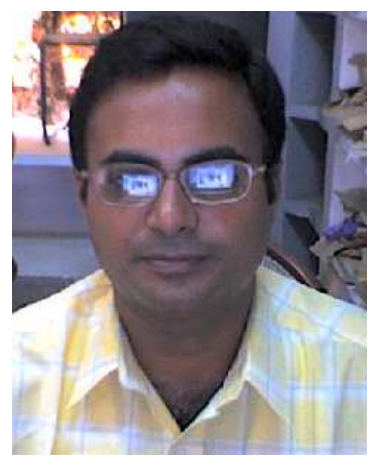

Krishnan Batri received the M.E. from Madurai Kamarj University in 2003. He is a Research Scholar with the Department of Computer Science and Engineering in the National Institute of Technology Tiruchirapalli, Tamil Nadu, India. Currently he is working as a Assistant Proffessor with the department of Computer Science and Engineering at Muthayammal Engineering College,Rasipuram, Tamilnadu, India . His research interests include Information Retrieval, Data fusion and Genetic algorithms. 